\title{
Recruiting patients for postgraduate medical training in a community family planning clinic: how do patients want to be asked?
}

\author{
Jennifer Heathcote
}

\begin{abstract}
Objectives To look at patients' views about the way in which they are recruited to assist with postgraduate medical training (i.e. Who is the best person to ask patients to participate? When is the best time for patients to be asked?) and to compare these with clinical practice.

Methods Questionnaire surveys of 103 female family planning clinic (FPC) patients and 40 Diploma of the Faculty of Family Planning (DFFP) instructing doctors. Patients were recruited from the waiting room of a community FPC, and DFFP instructing doctors from the North West of England were recruited at an updating meeting.
\end{abstract}

Results Patients preferred to be recruited by non-medical staff (i.e. receptionist and nurses). Few patients wanted to be asked by the training doctor. Only $9 \%$ would find it difficult to refuse a receptionist, $47 \%$ would find it difficult to refuse the instructing doctor and $65 \%$ would find it difficult to refuse the training doctor. In practice, the commonest person to recruit patients is the instructing doctor. Patients wanted to be given some time to consider the request; this was not always given.

Discussion and conclusions Patients may feel coerced into seeing training doctors because they find it difficult to refuse requests, particularly when they are being recruited by doctors. Non-medical staff may be more appropriate for the initial recruitment of patients. Patients need time to consider their involvement. The provision of written information may be useful. Further research is indicated to empower patients' decision-making and reduce the likelihood of coercion.

Keywords DFFP, patient consent, postgraduate, recruitment, training

J Fam Plann Reprod Health Care 2008; 34(1): 43-46

(Accepted 8 July 2007)

\section{Introduction}

"For the junior student in medicine and surgery it is a safe rule to have no teaching without a patient for a text, and the best teaching is that taught by the patient himself." (William Osler) ${ }^{1}$

Medical education at undergraduate and postgraduate level relies on the recruitment of patients who are willing to involve students or training doctors in their care. There is little in the literature about the recruitment process for postgraduate medical training; most references are to medical students.

This study sought the views of patients attending a family planning clinic (FPC) where postgraduate medical training takes place. The 'training doctors' are postregistration doctors, mainly general practice registrars or gynaecology senior house officers, who attend FPCs to gain clinical experience towards the Diploma of the Faculty of Family Planning (DFFP). These doctors all work with experienced Faculty 'instructing doctors' and, depending on their level of experience, they may observe or lead consultations in the presence of a more senior member of staff, or see patients on their own under the supervision of a Faculty instructing doctor. Practical procedures, such as intrauterine device and implant insertions, would always be performed in the presence of an experienced doctor.

Patient preferences were compared with the practice reported in a survey of family planning instructing doctors.

\footnotetext{
Central and Eastern Cheshire Primary Care Trust, Family Planning Clinic, Waters Green Medical Centre, Macclesfield, UK

Jennifer A Heathcote, MA, FFFP, Staff Grade
}

Correspondence to: Dr Jennifer Heathcote, Family Planning Clinic, Waters Green Medical Centre, First Floor, Sunderland Street, Macclesfield, Cheshire SK10 3BL, UK.

E-mail: drjennyheathcote@hotmail.com

\section{Key message points}

- Patients prefer to be recruited by non-medical staff and find it hard to say no to doctors. As a result, some patients may feel coerced to participate in doctor training.

- Patients want time to consider any request for their involvement in postgraduate medical training and this is not always given.

\section{Methods}

The study methodology was as described previously. ${ }^{2}$ Patients were recruited from the waiting room of a community FPC serving a mid-sized town in a rural part of Cheshire, UK. A questionnaire that had been pre-piloted in the same clinic sought quantitative and qualitative data about patients' experiences and expectations of their role in DFFP training.

Patients were initially approached by the receptionist on arrival at the clinic, and those who expressed an interest in taking part in the study were seen by the researcher. Further information was given verbally and in writing, and if the patient was able to give fully informed consent then the questionnaire was filled in by the patient in privacy. Most questionnaires were completed in the clinic, but stamped addressed envelopes were provided for patients who wished to return them later. The questionnaires were completely anonymous.

A different anonymous questionnaire was distributed at a doctors' updating day to seek the views and practice of instructing doctors from North West England. The aims of the study were described briefly at the start of the meeting, and completed questionnaires were collected as the doctors departed at the end of the day.

\section{Ethical approval}

Ethical approval for the study was granted by the Cheshire Local Research Ethics Committee. 


\section{Results and discussion}

A total of 103 patient questionnaires were returned, and 40 from the survey of instructing doctors, as described previously. ${ }^{2}$ Twenty-seven $(26 \%)$ patients remembered seeing a training doctor, and only one patient had had a training doctor involved in their care without being asked.

\section{Who is the best person to ask the patient?}

The person who makes the first approach to patients varies between clinics and between instructing doctors, and many doctors gave more than one reply when asked about their usual practice as follows: receptionist (4), nurse (22), instructing doctor (38), training doctor (3), notice in clinic (6), other ( 1 - youth workers) or they are not formally asked (0). One doctor commented:

"... it depends - usually the first clinician who realised they will be seen by a trainee. Could be the nurse who is putting her through or the instructing doctor or trainee depending on who is leading the consultation." (Doctor 1)

Of the patients in the survey who had been asked and could remember, $9 \%$ had been asked by the receptionist, $27 \%$ by a nurse, $9 \%$ by the training doctor and $55 \%$ by the instructing doctor.

Patients were asked whom they would prefer. Twelve people ticked more than one reply with varying combinations of options, but of those who gave one reply $31 \%$ preferred to be asked by the receptionist, $26 \%$ preferred the nurse, $1 \%$ the training doctor, $8 \%$ the instructing doctor and $34 \%$ would be happy with any of the above (though one patient did remark "not the training doctor though").

These statistics reflect patient preference, and do not correspond well with what happens in practice where the instructing doctor is the most likely recruiter. The literature mainly refers to consent to medical student training, but even here there is a lack of consensus. Berry et al. ${ }^{3}$ also found that patients preferred to be asked by someone other than the student or teaching doctor: $86 \%$ preferred a nurse. The authors felt that when the doctor or student asked it was "likely to put undue pressure on the patient to accept the student as part of their visit". Thus patient preference was to be sought by a non-physician and without the physician or student in the room.

O'Flynn and Rymer, ${ }^{4}$ however, raised concerns that if medical students are not involved in the consenting process then they will not learn the communication skills required. The Auckland School of Medicine debated this point ${ }^{5}$ and made a final (although not unanimously agreed) recommendation in favour of the student seeking consent for similar reasons.

There appears to be conflict between educational ideals and patient preference. Howe and Anderson 6 concluded that consent should be sought initially without the student being there; when given, consent should then be confirmed in the student's presence.

Table 1 Responses received to the following question: "If you were asked by any of the people listed below, how easy do you think it would be to say that you did not want to see a doctor who is being trained?"

\begin{tabular}{|c|c|c|c|c|}
\hline Questioner & $\begin{array}{l}\text { Very easy } \\
\text { to say no } \\
\text { (\%) }\end{array}$ & $\begin{array}{l}\text { Easy to } \\
\text { say no } \\
\text { (\%) }\end{array}$ & $\begin{array}{l}\text { Difficult } \\
\text { to say no } \\
\text { (\%) }\end{array}$ & $\begin{array}{l}\text { Very } \\
\text { difficult } \\
\text { to say no } \\
(\%)\end{array}$ \\
\hline Receptionist & 53 & 38 & 7 & 2 \\
\hline $\begin{array}{l}\text { Family planning } \\
\text { nurse }\end{array}$ & 31 & 57 & 10 & 2 \\
\hline Training doctor & 17 & 18 & 40 & 25 \\
\hline Instructing doctor & 24 & 29 & 35 & 12 \\
\hline
\end{tabular}

The ease with which patients felt able to refuse to participate varied according to the person who asked them (Table 1).

Patients found it more difficult to say no to the doctors than they would to either the nurse or receptionist. None of the studies quoted included reception staff as an option, but the FPC patients expressed a preference for the receptionist, and said that they would find it easier to say no to a receptionist. A policy published by the American Medical Association 7 suggested the use of patient advocates, and it may be that the receptionist could take on part of this role. Receptionists may not be able to give sufficient information for fully informed consent (being unable to comment on whether the training doctor would be seeing the patient with or without the instructing doctor, or discussing practical procedures) but they could give general information to patients as they arrive, either verbally or written, so patients can consider their response while waiting.

Nurses have been shown to play a valuable role in patient recruitment. One comment on the doctor's questionnaire was interesting:

"I find it very variable the number of patients who decline to see a trainee. I wonder if 'subconsciously' the nurse influences the decision by whether she likes the trainee (although this is denied)." (Doctor 2)

It is quite probable that nurses, and sometimes receptionists, may influence patients' decisions to agree to see a training doctor.

Patient empowerment is important; $12 \%$ of patients in the FPC study said they might agree to see a training doctor because "I would find it hard to say no". O'Flynn and Rymer" point out that the presumptions inherent in implied consent do not acknowledge the power imbalance; for a patient to opt out she must assert her right. Consent must be an active process, rather than agreeing because the patient would find it hard to object. The effect that saying no has on the patients must be considered: Patient 58, who ticked 'difficult to say no' to the instructing doctor, commented "feel guilty". This research suggests that current practice should be reformed to empower patients in their decision-making.

Some $65 \%$ of the patients would find it difficult or very difficult to say no to a request made by an instructing doctor who is, in practice, the most likely person to seek their consent. This suggests that there may have been some degree of unintended coercion of patients that needs to be addressed.

Patients preferred not to be asked by the training doctor. It may be more difficult to refuse permission to the person concerned than it would to a third party. (This might be of particular relevance when the patient has gender or ethnic preferences.) If consent is sought by a third party, this should be confirmed by the training doctor; being able to introduce themselves to patients is one of the consultation skills competencies by which they are assessed.

\section{When is the best time to ask patients for their consent?}

Patients need to be given a certain amount of information about their role before they can give informed consent to seeing a training doctor. Howe and Anderson ${ }^{6}$ and Benson et al. ${ }^{8}$ found that patients need time to consider the information given to them before deciding whether to become involved in training. FPC patients also reported needing time for mental preparation:

"I think people should always be warned if there will be a training doctor in the room. For me as long as I could prepare myself it wouldn't make any difference." (Patient 31) 
"As long as I know beforehand. I would feel unsure about seeing a male training doctor. But, although I have never been in this position - a friend of mine was not sure if it was here or another surgery/clinic but she was asked as she went in and it was very awkward for her to say no so important asked prior to this'. (Patient 13)

This may have influenced the patients' preference for receptionist-led recruitment; if the subject is broached by the receptionist then there is likely to be time for consideration in the waiting room, whereas patients rarely meet the training doctor or instructing doctor until immediately before the consultation.

\section{Should written information be provided?}

There is some evidence ${ }^{9,10}$ to show that patients prefer written as well as verbal information before seeing medical students. Berry et al. ${ }^{3}$ sent patients a letter detailing the student's involvement in their care. This gave them the opportunity to choose which part of the consultation they were happy for the student to observe or participate in and acted as a consent form. They found that after exposure to different ways of giving consent, significantly more patients said they would like to have a written explanation before giving permission. Only 3\% of patients in the control group (who were asked verbally just prior to their consultation) said that they would want written information; but of the group who had been given written and verbal information, $20 \%$ felt that they would want something in writing.

O'Flynn and Rymer ${ }^{4}$ also used the appointment letter to inform patients, and asked them to tell a nurse on arrival if they did not wish to see students. Only $41 \%$ of patients remembered reading this part of the letter. Notices in the clinic were only remembered by $4 \%$ of the patients. Since these methods were intended to allow patients to opt out, if less than half remembered seeing them one could not assume implied consent. Women in this study commented that being informed of a student's presence in the clinic was different from being asked whether a student could be present during their consultation. Advance notice of the presence of students was important as it increased women's feeling of choice about seeing them. The researchers recommended giving all patients a written sheet on arrival for them to specify their willingness or otherwise to see a student.

Written advance warning of the presence of training doctors at our FPC is not practical since appointment letters are not sent, and many patients prefer not to receive correspondence at home for reasons of confidentiality. Westberg et al. ${ }^{10}$ questioned patients attending a gynaecology outpatient clinic where medical students were being trained. They demonstrated that the patients felt significantly freer to decline to participate in the training when informed in advance, but this did not seem to jeopardise or negatively influence their inclination to see students compared with verbal information from the doctor at the time of their appointment.

The FPC in this study serves a population that has quite distinctive characteristics: it includes few individuals from ethnic minority groups, being over $98 \%$ white, ${ }^{11}$ and the general level of education is high $(28.4 \%$ are educated to degree level or beyond compared to the national average of $19.8 \%$ ). This may reduce the level of generalisability of the results.

There are published guidelines - one example relating to medical student teaching in the community ${ }^{12}$ - that could be adapted to fit local circumstances (Box 1).
Box 1 Patient consent: the use of patients for teaching in the community (excerpt from guidelines from the Department of Primary Care and Public Health, Cambridge University, Cambridge, UK) ${ }^{12}$

\section{Outline of basic standards}

- Patients attending for surgery appointments when students are likely to be present should be warned about this at the time of booking wherever possible.

- Patients should be informed that there is a student present at the time of checking in for the appointment.

- The doctor should wherever possible warn the patient that he/she has a student(s) sitting with him/her before the patient comes into the room.

- The patient should be given the opportunity to decline to see a student and it should be made clear that this does not prejudice the patient's care in any way.

- If patients are invited into the surgery for specific teaching sessions it should be made clear at the time of invitation what they may be expected to do (e.g. give a history, consent to be examined). In addition, it should be made clear what the purpose of the teaching session is.

- When patients are being discussed with the students and during teaching sessions, part of the teaching should be to involve the patient and to explain what is meant by the terms and why the teaching is being done in a certain way.

- Patients should be treated with respect and their dignity maintained at all times. Confidentiality should also be made clear.

- Students and doctors should always thank the patient for their time and assistance in the teaching session.

Prior to the teaching session, patients should be given some written information.

This information should include:

- The purpose of the examination/teaching session

- The status of the participating students

- The fact that the session is a training process

- The extent of the clinical care during the examination

- The potential risks and consequences of participation

- How the patient can ask questions about any aspect of the session.

Doctors and health care professionals who are arranging teaching sessions and examinations should be aware of a number of issues.

The issues to consider include:

- Consent: needs to be valid, informed and continuing.

- Confidentiality and data protection: care with storing information about patients, records, videotapes, etc.

- Duties and standards of care: when patients are seen in the primary care setting this is not usually a problem but it should be considered if patients are being invited to attend teaching or examination sessions outside normal clinical areas in the practice, community or hospital.

- Adverse or unexpected events: How would the patients be dealt with if they become acutely unwell in the course of the examination or teaching session? Who is available to help and what resuscitation facilities are there?

\section{Conclusions}

Patient involvement is essential to postgraduate medical training, and it is important that patients are able to give fully informed consent without any element of coercion. There is little in the literature about patients' views of the recruitment process, and this research suggests that what happens in practice is contrary to patient preferences. O'Flynn and Rymer4 have called for patients to be empowered to actively opt in; this research suggests that patients may find it difficult to opt out, particularly when they are being recruited by doctors. Non-medical staff may be more appropriate for the initial recruitment of patients.

Patients want time to consider the information given to them. When receptionists are involved in their recruitment, patients are more likely to have time to make a decision before seeing a doctor. Written information may assist the decision-making process; it could provide an opportunity for patients to indicate the level of involvement that the training doctor may have in their care. 
The study population has unusual demographics, and further research is indicated to assess the generalisability of these findings. This study calls for a review of practice at a local level and highlights the need for further research into patient involvement in postgraduate medical training.

Statements on funding and competing interests

Funding The author received a research grant from the North West Society of Sexual Medicine and Family Planning. The research was, however, undertaken independently of this organisation.

Competing interests None identified.

Author's note

This article formed part of a dissertation for an MA in Clinical Education at Edge Hill College, University of Lancaster, UK.

\section{Editor's note}

The third and final article by this author to be published in the Journal in April 2008 will examine what motivates patients to become involved in postgraduate medical training.

\section{References}

1 Osler W. The hospital as a college (Chapter XVI). In Aequanimatus, and Other Addresses. London, UK: HK Lewis, 1905.

2 Heathcote J. Postgraduate medial training: getting patients on board. J Fam Plann Reprod Health Care 2007; 33: 267-270.

3 Berry RE, O'Dell K, Meyer BA, Purwono U. Obtaining patient permission for student participation in obstetric-gynecologic outpatient visits: a randomised controlled trial. Am J Obstet Gynecol 2003; 189: 634-638.

4 O'Flynn N, Rymer J. Consent for teaching: the experience of women attending a gynaecology clinic. Med Educ 2003; 37:1109-1114.

5 Grant V. Patient involvement in clinical teaching. J Med Ethics 1994; 20: 244-250.

6 Howe A, Anderson J. Involving patients in medical education. BMJ 2003; 327: 326-329.

7 Council on Ethical and Judicial Affairs of the American Medica Association. Medical students' involvement in patient care. $J$ Clin Ethics 2001; 12: 111-115.

8 Benson J, Quince T, Hibble A, Fanshawe T, Emery J. Impact on patients of expanded, general practice based, student teaching: observational and qualitative study BMJ 2005; 331 89-92.

9 Welfare MR, Price CIM, Han SW, Barton JR. Experiences of volunteer patients during undergraduate examinations: printed information can lead to greater satisfaction. Med Educ 1999; 33: 165-169.

10 Westberg K, Lynöe N, Lalos A, Löfgren M, Sandlund M. Getting informed consent from patients to take part in the clinical training of students: randomised trial of two strategies. BMJ 2002; 323: 488

11 Office for National Statistics. National Census, 2001 Neighbourhood statistics for Macclesfield (Local Authority) http://www.neighbourhood.statistics.gov.uk/dissemination/Lead KeyFigures.do $? a=3 \& b=276900 \& c=S K 9+5 D W \& d=13 \& e=15 \& g$ $=429156 \& \mathrm{i}=1001 \times 1003 \times 1004 \& \mathrm{~m}=0 \& \mathrm{r}=0 \& \mathrm{~s}=1193706679904 \&$ enc $=1$ [Accessed 5 May 2007]

12 Guidelines from the Department of Primary Care and Public Health, Cambridge University, Cambridge, UK http://www.gpeg.medschl.cam.ac.uk/pages/standards/consent. html [Information temporarily inaccessible due to website redevelopment].

\section{VOLUNTEERS NEEDED TO WRITE JOURNAL ARTICLE REVIEWS}

The Journal regularly reviews articles from related publications (see page 18) and is looking to recruit more volunteers to compile these short reviews.

For further information and/or to offer your services (at most once or twice a year) please e-mail the Journal Editorial Office at journal@fsrh.org. Please provide your contact details (mail/e-mail addresses) together with a note of any special interests and/or expertise to assist us in allocating relevant articles to individual reviewers.

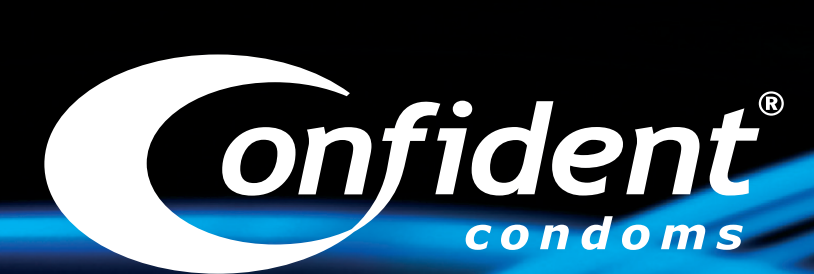

\section{A new level of protection}

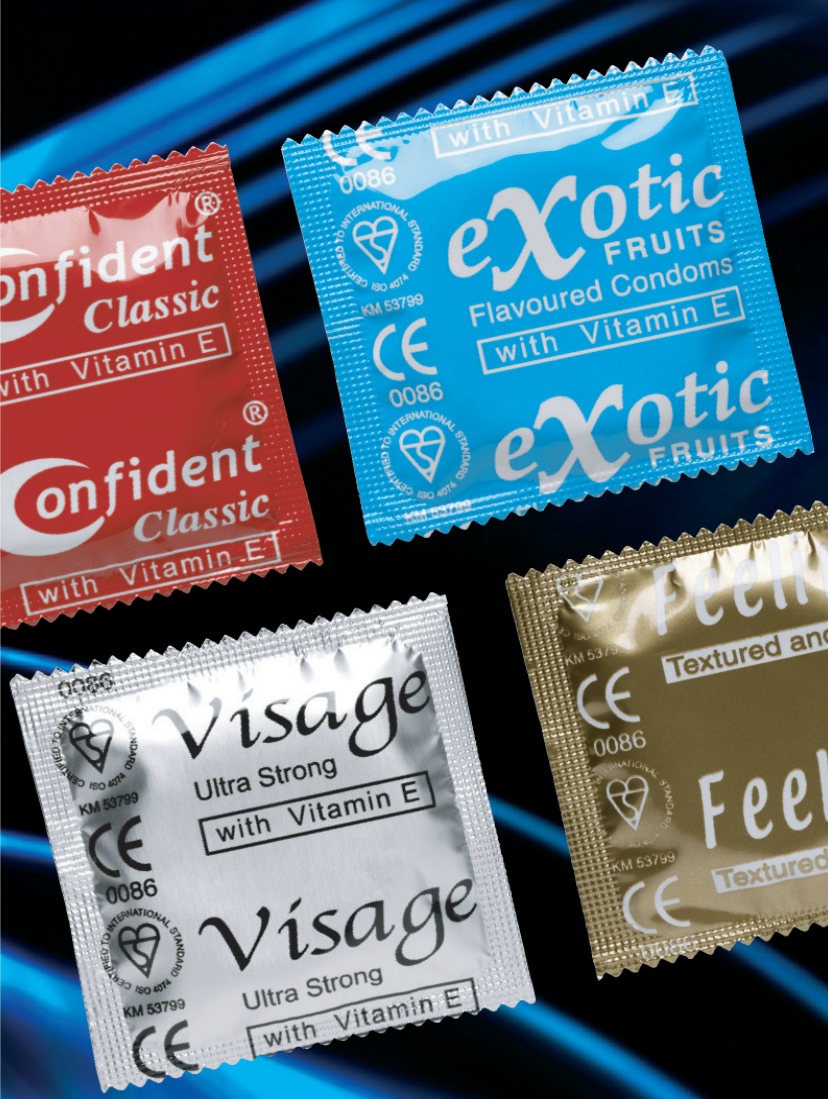

Condoms odour masked and IUbricated with Vitamin $E$

\section{Competitively priced packs in presentation boxes}

$$
\begin{aligned}
& \text { Customer support, advice, } \\
& \text { presentations and samples }
\end{aligned}
$$

Anatomically shaped for greater comfort and sensitivity

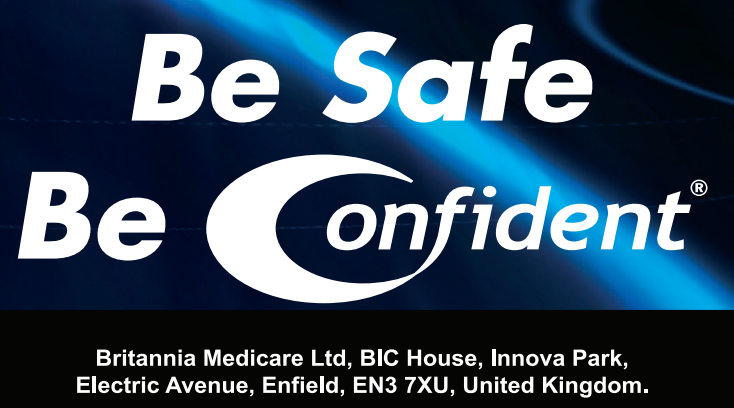

$T+44(0) 2083501402 F+44(0) 2083720112$ info@britanniamedicare.com 